\title{
Efektivitas Pemanfaatan Dana Klaim Asuransi Usahatani Padi (AUTP) di Subak Sengempel, Desa Bongkasa, Kecamatan Abiansemal Kabupaten Badung
}

\author{
ANAK AGUNG ARISTA SATWIKANI, I GUSTI AYU AGUNG AMBARAWATI, \\ I DEWA GEDE RAKA SARJANA
}

Program Studi Agribisnis, Fakultas Pertanian, Universitas Udayana

J1. PB Sudirman Denpasar 80232

Email: arista.satwikani@gmail.com

annie.ambarawati@gmail.com

\begin{abstract}
Effectiveness Of Utilization Of The Rice Crop Insurance (AUTP) Claims Fund at Subak Sengempel, Bongkasa Village, Abiansemal District Badung Regency
\end{abstract}

AUTP was launched by the government as an effort to protect farmers from crop failure by providing claims that can be used as capital for the next season. This research aims to determine the response of farmers and the effectiveness of AUTP claims fund utilization. The research was done purposively in Subak Sengempel, Bongkasa Village, Abiansemal Sub-district of Badung Regency. Samples were 62 farmers who received claims fund. Data were collected through interviews, observation and documentation. Data analysis is descriptive qualitative and quantitative. The results shows that farmers respond positively to the AUTP program in terms of knowledge and attitude. The average knowledge of farmers reached $80 \%$ of the total expected knowledge about AUTP and the farmer's attitude were agreed with the average score is 4.10 . Furthermore, by type of fund usage is effective category which is $90.32 \%$ of farmers use as a capital for rice cultivation for the next planting season. The utilization of AUTP claims funds viewed from the claims capability is effective to cover $110.31 \%$ cost of farming production per 0.25 ha up to planting and maintenance stages. In this research can be suggested the AUTP program needs to be continued and coordination between the parties involved should be maintained.

Keywords: claims fund utilization, rice crop insurance, farmers response.

\section{Pendahuluan}

\subsection{Latar Belakang}

Permasalahan utama dalam mewujudkan ketahanan pangan di Indonesia saat ini berkaitan dengan fakta bahwa pertumbuhan permintaan pangan lebih cepat dari pertumbuhan penyediaannya (Suryana, 2002). Namun, upaya pemenuhan produksi terkendala perubahan iklim yang mempengaruhi cuaca dan intensitas serangan OPT. 
Pemerintah Indonesia telah meluncurkan program Asuransi Usahatani Padi (AUTP) sebagai upaya melindungi petani dari dampak perubahan iklim. Program AUTP merupakan implementasi UU Nomor 19 Tahun 2013 tentang Perlindungan dan Pemberdayaan Petani, yang ditindaklanjuti penerbitan Permentan Nomor 40 Tahun 2015 tentang Fasilitasi Asuransi Pertanian. Program AUTP mulai dilaksanakan di Indonesia pada bulan Oktober 2015 sesuai Keputusan Menteri Pertanian Nomor: 417.1/Kpts/HK.150/B/12/2015 tentang Pedoman Bantuan Premi Usahatani Padi.

Ketentuan mengikuti program AUTP adalah membayar premi sebesar 3\% dari nilai pertanggungan sebesar Rp 6.000.000,00/ha/MT. Total premi asuransi sebesar Rp 180.000,00/ha/MT. Pemerintah memberi subsidi 80\% yaitu Rp 144.000,00/ha/MT dan petani membayar premi sisanya sebesar $20 \%$ atau Rp 36.000,00/ha/MT. Pemerintah bekerjasama dengan PT Jasindo sebagai penanggung risiko dan membantu melaksanakan program AUTP di seluruh wilayah Indonesia.

Sejak program AUTP dilaksanakan pada Oktober 2015, Provinsi Bali sebagai salah satu sentra produksi padi kemudian ikut serta dalam program AUTP. Luas areal peserta AUTP di Provinsi Bali mengalami perkembangan dari MT Oktober 2015 Maret 2016 seluas 6.087,84 ha menjadi 21.510,25 ha pada MT April - September 2016 mengalami peningkatan sebesar dua ratus lima puluh tiga persen.

Selama MT Oktober 2015 - September 2016 luas klaim AUTP di Provinsi Bali mencapai $1,26 \%$ dari total luas lahan yang diasuransikan. Luas klaim terbesar terdapat di Kabupaten Tabanan, namun proporsi luas klaim dengan luas areal yang diasuransikan terbesar terdapat di Kabupaten Badung mencapai 5,63\%. Terdapat tiga subak di Kabupaten Badung yang mendapatkan klaim akibat serangan tikus yaitu Subak Sengempel seluas 22,96 ha (87,63\%), Subak Sangeh 2,73 ha (10,41\%) dan Subak Tanah Putih 0,51 ha $(1,94 \%)$ dari total klaim di Kabupaten Badung.

Subak Sengempel dihadapkan pada tingginya serangan tikus dan merupakan daerah endemik tungro (BPP Kecamatan Abiansemal, 2015). Oleh karena itu, pada MT Oktober 2015 - Maret 2016 Subak Sengempel mengasuransikan lahan seluas 97 ha dan total premi yang dibayarkan Rp 2.117.160,- dengan jumlah petani yang menjadi peserta sebanyak 247 orang.

Serangan tikus yang terjadi pada Mei 2016 mengakibatkan 22,96 ha lahan mengalami gagal panen sehingga petani mendapatkan klaim sebesar Rp 137.760.000,-. Pemberian klaim ini bertujuan agar petani memiliki modal berusahatani di musim tanam berikutnya. Berdasarkan latar belakang tersebut, menarik untuk dikaji mengenai respons petani terhadap program AUTP dan efektivitas pemanfaatan dana klaim AUTP di Subak Sengempel.

\subsection{Tujuan Penelitian}

Adapun tujuan dari penelitian ini untuk (1) mengetahui respons petani terhadap program AUTP dan (2) mengetahui efektivitas pemanfaatan dana klaim AUTP menurut jenis penggunaan dana dan perbandingan dana klaim dengan biaya produksi di Subak Sengempel, Desa Bongkasa, Kecamatan Abiansemal Kabupaten Badung. 


\section{Metode Penelitian}

\subsection{Lokasi dan Waktu Penelitian}

Penelitian dilakukan di Subak Sengempel, Desa Bongkasa, Kecamatan Abiansemal Kabupaten Badung. Penentuan lokasi penelitian secara sengaja. Waktu pengumpulan data dari bulan Mei - Agustus 2017.

\subsection{Sumber, Jenis dan Metode Pengumpulan Data}

\subsubsection{Sumber dan jenis data}

Menurut sumbernya, data primer diperoleh dari wawancara langsung dengan petani penerima klaim AUTP, pangliman dan PPL. Data sekunder diperoleh dari dokumen yang dimiliki Subak Sengempel, PT Jasindo, BPP Kecamatan Abiansemal, dan Dinas Pertanian Provinsi Bali.

Jenis data terdiri dari data kualitatif dan kuantitatif. Data kualitatif meliputi pengetahuan dan sikap sebagai respons petani terhadap program AUTP. Data kuantitatif meliputi karakteristik umum, jumlah petani pengguna dana klaim (padi/non-padi), biaya produksi, luas, dan besarnya klaim.

\subsubsection{Metode pengumpulan data}

Data respons petani terhadap program AUTP serta efektivitas pemanfaatan dana klaim AUTP dikumpulkan melalui kuisioner, wawancara mendalam, observasi, serta dokumentasi.

\subsection{Populasi dan Sampel}

Populasi penelitian adalah semua petani penerima dana klaim AUTP MT Oktober 2015 - Maret 2016 sebanyak 165 orang. Penarikan sampel diperoleh 62 orang menggunakan rumus Slovin menurut Sugiyono (2011) sehingga jumlahnya representatif. Metode pengambilan sampel digunakan simple random sampling dengan cara undian.

\subsection{Variabel Penelitian dan Pengukuran}

Variabel pengukuran terdiri dari pengetahuan serta sikap (sosialisasi dan pelaksanaan program), jenis penggunaan dana (padi/non-padi), dan biaya produksi (sarana produksi, tenaga kerja luar keluarga dan iuran).

\subsection{Metode Analisis Data}

Analisis data dilakukan guna memecahkan permasalahan yang diteliti setelah data selesai dikumpulkan. Metode analisis data dalam penelitian ini digunakan deskriptif kualitatif dan kuantitatif.

Analisis data deskriptif kualitatif untuk menggambarkan karakteristik responden dan respons terkait pengetahuan dan sikap petani. Pengukuran pengetahuan petani menggunakan pernyataan positif dan negatif dengan pilihan jawaban ya dan tidak.

Proporsi jawaban responden dapat diketahui pada pernyataan positif dengan ketentuan pemberian kode 1 untuk jawaban ya sedangkan kode 2 untuk jawaban tidak, dan pernyataan negatif sebaliknya. Analisis data dilakukan dengan melihat frekuensi 
responden yang memahami dengan total responden lalu dikalikan $100 \%$ sehingga diperoleh persentase pengetahuan petani. Persentase pengetahuan tersebut selanjutnya dikategorikan sesuai Tabel 1.

Tabel 1.

Kategori Pengetahuan Petani Terhadap Program AUTP

\begin{tabular}{cc}
\hline Persentase & Kategori \\
\hline $1-20$ & Sangat Kurang Baik \\
$21-40$ & Kurang Baik \\
$41-60$ & Cukup Baik \\
$61-80$ & Baik \\
$81-100$ & Sangat Baik \\
\hline
\end{tabular}

Pengukuran sikap petani terhadap program AUTP menggunakan skala Likert. Terdapat lima kategori jawaban yaitu Sangat Tidak Setuju (STS), Tidak Setuju (TS), Ragu-Ragu (R), Setuju (S), sampai Sangat Setuju (SS) yang dapat dipilih untuk menjawab pernyataan yang tersedia.

Ketentuan pemberian skor pada pernyataan positif adalah skor 1 untuk jawaban Sangat Tidak Setuju (STS), skor 2 Tidak Setuju (TS), skor 3 Ragu-Ragu (R), skor 4 Setuju (S), dan skor 5 Sangat Setuju (SS). Pemberian skor pada pernyataan negatif merupakan kebalikan dari skor pernyataan positif. Berdasarkan pada skor yang diperoleh selanjutnya dirata-ratakan, dan dikategorikan sesuai Tabel 2.

Tabel 2.

Kategori Skor Sikap Petani Terhadap Program AUTP

\begin{tabular}{cc}
\hline Nilai Skor & Kategori \\
\hline $1-<1,8$ & Sangat Tidak Setuju \\
$1,8-<2,6$ & Tidak Setuju \\
$2,6-<3,4$ & Cukup \\
$3,4-<4,2$ & Setuju \\
$4,2-<5,0$ & Sangat Setuju \\
\hline
\end{tabular}

Analisis data kuantitatif untuk menggambarkan efektivitas pemanfaatan dana klaim menurut jenis penggunaan dan besarnya biaya produksi dengan menggunakan pendekatan rumus pencapaian efektivitas menurut Arikunto (2002) yaitu:

Persentase efektivitas pemanfaatan dana $=\frac{\text { Realisasi pemanfaatan dana klaim }}{\text { Target pemanfaatan dana }} \times 100 \%$

Keterangan:

Realisasi pemanfaatan dana klaim = hasil pemanfaatan dana yang telah diwujudkan

Target pemanfaatan dana klaim = tujuan program yang ingin dicapai 
Pemanfaatan dana klaim AUTP ditinjau berdasarkan dua aspek meliputi:

1) Jenis penggunaan dana klaim AUTP

Analisis data menggunakan rumus menurut Arikunto (2002) yang dimodifikasi sebagai berikut.

Persentase penggunaan klaim $=\frac{\text { Jumlah petani pengguna dana klaim AUTP }}{\text { Total Responden }} \times 100 \%$

Hasil yang diperoleh selanjutnya dikategorikan sesuai kategori pencapaian tingkat efektivitas program seperti tersaji pada Tabel 3.

Tabel 3.

Kategori Pencapaian Tingkat Efektivitas Program

\begin{tabular}{cc}
\hline Persentase & Kategori \\
\hline $0-40$ & Tidak Efektif \\
$41-60$ & Cukup Efektif \\
$61-100$ & Efektif \\
\hline
\end{tabular}

Sumber: Arikunto (2002)

2) Perbandingan dana klaim AUTP dengan biaya produksi usahatani

Untuk melihat perbandingan dana klaim dengan biaya produksi usahatani digunakan rumus menurut Arikunto (2002) yang dimodifikasi sebagai berikut.

Persentase $=\frac{\text { Rata }- \text { Rata Dana Klaim AUTP }(\mathrm{Rp} / \mathrm{ha})}{\text { Rata-Rata Biaya Produksi Usahatani Padi (Rp/ha) }} \times 100 \%$

Mengacu pada tujuan pemberian klaim AUTP sebagai modal penanaman kembali di musim berikutnya sehingga dari persentase yang diperoleh selanjutnya dikategorikan: jika persentase $<100 \%$ maka klaim dinyatakan belum efektif, sedangkan persentase $\square$ $100 \%$ dinyatakan efektif menutup biaya produksi.

\section{Hasil Penelitian}

\subsection{Karakteristik Umum Responden}

Mayoritas responden $(62,90 \%)$ berumur produktif sehingga memungkinkan bekerja lebih baik dengan kondisi fisik yang kuat. Menurut BPS (2012) umur produktif berada pada rentang 15-64 tahun. Responden didominasi laki-laki (95\%). Pendidikan responden tergolong rendah karena mayoritas $(74,19 \%)$ menyelesaikan pendidikan tingkat sekolah dasar. Pendidikan yang tergolong rendah melatarbelakangi mayoritas responden $(79,03 \%)$ memilih menjadi petani sebagai pekerjaan pokok dan peternak sebagai pekerjaan sampingan. Mayoritas lahan yang diusahakan $(83,87 \%)$ adalah milik sendiri dengan rata-rata luas garapan 0,25 ha. Hal ini menunjukkan bahwa mayoritas responden $(96,77 \%)$ tergolong petani gurem yang menggarap lahan kurang dari 0,50 ha (BPS, 2013).

\subsection{Respons Petani Terhadap Program AUTP}




\subsubsection{Pengetahuan petani terhadap program AUTP}

Berdasarkan hasil penelitian, secara keseluruhan pengetahuan petani tentang program AUTP berada pada kategori baik, dengan pemahaman terhadap sosialisasi dan pelaksanaan program mencapai $80 \%$ (Gambar 1).

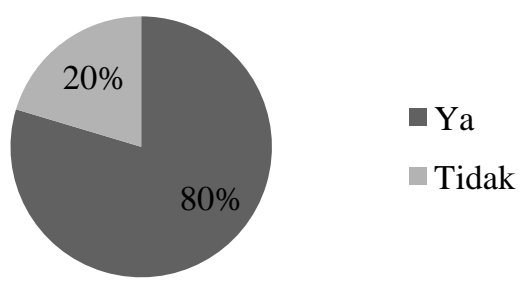

Gambar 1.

Persentase Pencapaian Pengetahuan Petani Terhadap Program AUTP

Program AUTP pertama kali dilaksanakan pada Oktober Tahun 2015 dan dilakukan sosialisasi untuk mengenalkan petani sehingga pelaksanaannya sesuai tujuan, manfaat dan sasaran program. Secara lebih rinci pemahaman petani terhadap sosialisasi program AUTP disajikan pada Tabel 4.

\section{Tabel 4.}

Pengetahuan Petani Terhadap Sosialisasi Program AUTP di Subak Sengempel, Desa Bongkasa, Kecamatan Abiansemal, Kabupaten Badung

\begin{tabular}{|c|c|c|c|c|c|c|}
\hline \multirow{3}{*}{ No } & \multirow{3}{*}{ Indikator } & \multicolumn{4}{|c|}{ Pencapaian } & \multirow{3}{*}{ Kategori } \\
\hline & & \multicolumn{2}{|c|}{ Paham } & \multicolumn{2}{|c|}{ Tidak Paham } & \\
\hline & & Orang & $\%$ & Orang & $\%$ & \\
\hline 1 & $\begin{array}{l}\text { Pengetahuan tentang adanya } \text { sosialisasi } \\
\text { pengenalan program AUTP }\end{array}$ & 56 & 90 & 6 & 10 & Sangat Baik \\
\hline 2 & Pengetahuan tentang tujuan AUTP sebagai pengalihan resiko & 53 & 85 & 9 & 15 & Sangat Baik \\
\hline 3 & $\begin{array}{l}\text { Pengetahuan tentang manfaat pemberian klaim sebagai modal } \\
\text { penanaman padi kembali }\end{array}$ & 55 & 89 & 7 & 11 & Sangat Baik \\
\hline 4 & Pengetahuan tentang sistem pembagian premi AUTP & 39 & 63 & 23 & 37 & Baik \\
\hline 5 & Pengetahuan tentang subsidi premi pemerintah & 41 & 66 & 21 & 34 & Baik \\
\hline 6 & Pengetahuan tentang premi yang dibayar petani per hektar & 50 & 81 & 12 & 19 & Sangat Baik \\
\hline 7 & Pengetahuan tentang klaim AUTP per hektar & 52 & 84 & 10 & 16 & Sangat Baik \\
\hline 8 & Pengetahuan tentang jenis kerusakan yang ditanggung AUTP & 49 & 79 & 13 & 21 & Baik \\
\hline & Rata-Rata & 49 & 80 & 13 & 20 & Baik \\
\hline
\end{tabular}

Sumber: Data primer, diolah (2017)

Pengetahuan petani terhadap pelaksanaan program AUTP mencapai 80\%. Hal ini ditinjau dari proses pendaftaran, pengajuan dan pembayaran klaim AUTP secara umum telah dipahami dengan baik. Secara lebih lengkap disajikan pada Tabel 5. 
Tabel 5.

Pengetahuan Petani Terhadap Pelaksanaan Program AUTP di Subak Sengempel, Desa Bongkasa, Kecamatan Abiansemal Kabupaten Badung

\begin{tabular}{|c|c|c|c|c|c|c|}
\hline \multirow{3}{*}{ No } & \multirow{3}{*}{ Indikator } & \multicolumn{4}{|c|}{ Pencapaian } & \multirow{3}{*}{ Kategori } \\
\hline & & \multicolumn{2}{|c|}{ Paham } & \multicolumn{2}{|c|}{ Tidak Paham } & \\
\hline & & Orang & $\%$ & Orang & $\%$ & \\
\hline \multirow[t]{4}{*}{1} & Pendaftaran AUTP & & & & & \\
\hline & $\begin{array}{l}\text { a. Syarat pendaftaran AUTP adalah memiliki KTP } \\
\text { / kartu identitas }\end{array}$ & 52 & 84 & 10 & 16 & Sangat Baik \\
\hline & $\begin{array}{l}\text { b. Umur maksimal tanaman padi yang } \\
\text { diasuransikan } 30 \text { hari }\end{array}$ & 44 & 71 & 18 & 29 & Baik \\
\hline & $\begin{array}{l}\text { c. Penilaian kelayakan peserta AUTP dilakukan } \\
\text { oleh petugas asuransi }\end{array}$ & 51 & 82 & 11 & 18 & Sangat Baik \\
\hline \multirow[t]{5}{*}{2} & Pengajuan Klaim AUTP & & & & & \\
\hline & $\begin{array}{l}\text { a. Batas waktu maksimal pengajuan klaim setelah } \\
\text { kerusakan adalah } 7 \text { hari }\end{array}$ & 55 & 89 & 7 & 11 & Sangat Baik \\
\hline & $\begin{array}{l}\text { b. Pengajuan klaim tanpa menunggu pemeriksaan } \\
\text { oleh POPT-PHP/PPL }\end{array}$ & 49 & 79 & 13 & 21 & Baik \\
\hline & $\begin{array}{l}\text { c. Bukti kerusakan tidak boleh hilang sebelum } \\
\text { diverifikasi petugas asuransi }\end{array}$ & 54 & 87 & 8 & 13 & Sangat Baik \\
\hline & $\begin{array}{l}\text { d. Pengajuan klaim jika tingkat kerusakan akibat } \\
\text { OPT minimal } 75 \% \text { per petak alami }\end{array}$ & 45 & 73 & 17 & 27 & Baik \\
\hline \multirow[t]{4}{*}{3} & Pembayaran Klaim & & & & & \\
\hline & $\begin{array}{l}\text { a. Batas waktu maksimal pembayaran klaim } \\
\text { adalah } 14 \text { hari }\end{array}$ & 46 & 74 & 16 & 26 & Baik \\
\hline & $\begin{array}{l}\text { b. Pembayaran klaim kepada masing-masing } \\
\text { petani melalui Ketua Subak }\end{array}$ & 53 & 85 & 9 & 15 & Sangat Baik \\
\hline & Rata - Rata & 50 & 80 & 12 & 20 & Baik \\
\hline
\end{tabular}

Sumber: Data primer, diolah (2017)

\subsubsection{Sikap petani terhadap program AUTP}

Berdasarkan hasil penelitian, sikap petani tergolong setuju terhadap program AUTP dilihat dari sosialisasi dan pelaksanaan program AUTP dengan rata-rata skor 4,10. Secara lebih rinci, petani menunjukkan sikap setuju terhadap sosialisasi program dengan rata-rata skor 4,08. Hal ini dapat diartikan sosialisasi telah berlangsung dengan baik di Subak Sengempel (Tabel 6).

Tabel 6.

Sikap Petani Terhadap Sosialisasi Program AUTP di Subak Sengempel, Desa Bongkasa, Kecamatan Abiansemal, Kabupaten Badung

\begin{tabular}{clcc}
\hline \multirow{2}{*}{ No } & \multicolumn{1}{c}{ Indikator } & $\begin{array}{c}\text { Pencapaian } \\
\text { Skor }\end{array}$ & \multirow{2}{*}{ Kategori } \\
\hline 1 & Kemudahan memahami penjelasan yang diberikan & 4,15 & Setuju \\
2 & Kesulitan berinteraksi dengan petugas asuransi & 3,90 & Tidak Setuju \\
3 & Manfaat sosialisasi untuk menambah wawasan petani & 4,19 & Setuju \\
\hline & Rata-Rata & 4,08 & Setuju \\
\hline
\end{tabular}

Sumber: Data primer, diolah (2017)

Sikap petani terhadap pelaksanaan program AUTP tergolong setuju dengan ratarata skor 4,16. Hal ini berkaitan dengan respons petani terhadap program AUTP ditinjau dari proses pendaftaran, pengajuan, pembayaran klaim dan pelayanan program AUTP yang telah terlaksana dengan baik (Tabel 7). 
Tabel 7.

Sikap Petani Terhadap Pelaksanaan Program AUTP di Subak Sengempel, Desa Bongkasa, Kecamatan Abiansemal, Kabupaten Badung

\begin{tabular}{|c|c|c|c|}
\hline No & Indikator & $\begin{array}{l}\text { Pencapaian } \\
\text { Skor }\end{array}$ & Kategori \\
\hline \multirow[t]{5}{*}{1} & Pendaftaran AUTP & & \\
\hline & a. Kesulitan memenuhi persyaratan pendaftaran & 4,00 & Tidak Setuju \\
\hline & $\begin{array}{l}\text { b. Kesesuaian premi dengan manfaat yang } \\
\text { diperoleh petani }\end{array}$ & 4,10 & Setuju \\
\hline & $\begin{array}{l}\text { c. Penerimaan terhadap sistem pembagian premi } \\
\text { yang ditentukan pemerintah }\end{array}$ & 4,18 & Setuju \\
\hline & $\begin{array}{l}\text { d. Penerimaan terhadap jenis OPT yang dijamin } \\
\text { asuransi telah mencakup semua jenis OPT yang } \\
\text { menyerang padi }\end{array}$ & 3,89 & Setuju \\
\hline \multirow[t]{3}{*}{2} & Pengajuan Klaim AUTP & & \\
\hline & a. Kesulitan petani melaporkan kerusakan & 3,97 & Tidak Setuju \\
\hline & $\begin{array}{l}\text { b. Penerimaan terhadap jumlah klaim AUTP per } \\
\text { hektar }\end{array}$ & 4,08 & Setuju \\
\hline \multirow[t]{3}{*}{3} & Pembayaran Klaim AUTP & & \\
\hline & a. Proses pembayaran klaim tepat waktu & 4,00 & Setuju \\
\hline & $\begin{array}{l}\text { b. Kesesuaian besar klaim yang diterima petani } \\
\text { dengan hasil verifikasi Jasindo }\end{array}$ & 4,19 & Setuju \\
\hline \multirow[t]{11}{*}{4} & Pelayanan Program AUTP & & \\
\hline & $\begin{array}{l}\text { a. Rasa aman berusahatani setelah mengikuti } \\
\text { program AUTP }\end{array}$ & 4,10 & Setuju \\
\hline & $\begin{array}{l}\text { b. Ketidakpuasan petani dengan pelayanan } \\
\text { program }\end{array}$ & 4,16 & Tidak Setuju \\
\hline & $\begin{array}{l}\text { c. Tercapainya tujuan AUTP ditentukan dari peran } \\
\text { petugas asuransi, POPT/PHP dan PPL dalam } \\
\text { memberi pelayanan kepada petani }\end{array}$ & 4,21 & Sangat Setuju \\
\hline & $\begin{array}{l}\text { d. Ketidaksesuaian pelayanan petugas asuransi } \\
\text { dengan prosedur AUTP }\end{array}$ & 3,9 & Tidak Setuju \\
\hline & $\begin{array}{l}\text { e. Petugas asuransi lambat dalam menanggapi } \\
\text { laporan kerusakan }\end{array}$ & 4,10 & Tidak Setuju \\
\hline & $\begin{array}{l}\text { f. Kemampuan dan pengetahuan petugas asuransi } \\
\text { menghitung luas kerusakan dengan tepat }\end{array}$ & 3,89 & Setuju \\
\hline & $\begin{array}{l}\text { g. POPT/PHP terampil dan handal menangani } \\
\text { kerusakan }\end{array}$ & 4,27 & Sangat Setuju \\
\hline & h. Kesulitan berkomunikasi dengan POPT/PHP & 4,31 & $\begin{array}{l}\text { Sangat Tidak } \\
\text { Setuju }\end{array}$ \\
\hline & i. Kelayakan program AUTP untuk dilanjutkan & 4,52 & Sangat Setuju \\
\hline & Rata-Rata & 4,16 & Setuju \\
\hline
\end{tabular}

Sumber: Data primer, diolah (2017)

\subsection{Efektivitas Pemanfaatan Dana Klaim AUTP}

\subsubsection{Jenis penggunaan dana klaim AUTP}

Hasil penelitian menunjukkan penggunaan dana klaim AUTP di Subak Sengempel termasuk efektif. Mayoritas petani (90,32\%) menggunakan dana klaim untuk berusahatani padi di musim berikutnya dan sisanya $(9,68 \%)$ berusahatani jagung manis. Hal ini menunjukkan bahwa sebagian besar petani sudah menggunakan dana klaim sesuai dengan tujuan AUTP yaitu untuk berusahatani padi. 


\subsubsection{Perbandingan dana klaim dengan biaya produksi usahatani}

Biaya produksi usahatani dari bulan April - Juli 2017 digunakan sebagai perbandingan. Pada Tabel 8 diketahui biaya produksi sebelum panen yang dikeluarkan adalah Rp 1.359.782,00. Jika dibandingkan dengan klaim AUTP sebesar Rp 1.500.000,00 sehingga dapat disimpulkan klaim AUTP efektif menutupi biaya produksi sebesar 110,31\% dimana terdapat kelebihan dana sebesar Rp 140.218,00.

Hal ini telah sesuai dengan tujuan AUTP untuk membantu petani yang mengalami gagal panen dalam menyediakan modal penanaman kembali di musim tanam berikutnya. Klaim AUTP dapat menutupi biaya produksi karena adanya subsidi benih, pupuk dan pajak dari pemerintah pusat dan Kabupaten Badung.

\section{Tabel 8.}

Perbandingan Dana Klaim dengan Biaya Produksi Usahatani di Subak Sengempel Desa Bongkasa, Kecamatan Abiansemal, Kabupaten Badung

\begin{tabular}{|c|c|c|c|c|c|c|}
\hline \multirow{2}{*}{ Uraian Biaya } & \multicolumn{4}{|c|}{ Per Rata-Rata Luas Garapan $(0,25 \mathrm{Ha})$} & \multirow{2}{*}{$\begin{array}{l}\text { Persentase } \\
\quad(\%)\end{array}$} & \multirow{2}{*}{ Keterangan } \\
\hline & Satuan & Jumlah & Harga $(\mathrm{Rp})$ & Nilai $(\mathrm{Rp})$ & & \\
\hline \multicolumn{7}{|c|}{ 1. Biaya Sarana Produksi } \\
\hline $\begin{array}{l}\square \quad \text { Benih Padi } \square \\
\square \quad \text { Pupuk } \square\end{array}$ & $\mathrm{Kg}$ & 8,84 & 3.000 & 26.516 & 1,95 & Subsidi Rp 7.000/kg \\
\hline Urea & $\mathrm{Kg}$ & 50,03 & 2.000 & 100.065 & 7,36 & Subsidi Rp 4.060/kg \\
\hline NPK Phonska & $\mathrm{Kg}$ & 75 & 1.200 & 90.000 & 6,62 & Subsidi Rp 7.000/kg \\
\hline \multicolumn{7}{|l|}{$\square \quad$ Pestisida $\square$} \\
\hline Confidor & $\mathrm{Kg}$ & 0,1 & 30.000 & 30.000 & 2,21 & \\
\hline Virtako & Liter & 0,02 & 110.000 & 220.142 & 16,19 & \\
\hline Cruiser & $\mathrm{Kg}$ & 0,01 & 35.000 & 17.511 & 1,29 & \\
\hline \multicolumn{4}{|c|}{ Sub total biaya sarana produksi } & 484.234 & 35,61 & \\
\hline \multicolumn{7}{|c|}{ 2.Tenaga Kerja Luar Keluarga } \\
\hline \multicolumn{4}{|c|}{ Pengolahan Lahan $\square$} & 500.323 & 36,79 & $\mathrm{Rp} 2.000 .000 / \mathrm{Ha}$ \\
\hline \multicolumn{4}{|c|}{$\square \quad$ Penanaman $\square$} & 350.226 & 25,76 & Rp $1.400 .000 / \mathrm{Ha}$ \\
\hline \multicolumn{4}{|c|}{ Sub total biaya tenaga kerja luar keluarga } & 850.548 & 62,55 & \\
\hline \multicolumn{7}{|l|}{ 3. Biaya Lain-Lain } \\
\hline \multicolumn{4}{|l|}{$\square \quad$ Iuran Subak $\square$} & 25.000 & 1,84 & $\mathrm{Rp} \mathrm{100.000/Ha/MT}$ \\
\hline \multicolumn{4}{|c|}{ Sub total biaya lain-lain } & 25.000 & 1,84 & \\
\hline \multicolumn{4}{|c|}{ Total Biaya } & 1.359 .782 & & \\
\hline \multicolumn{4}{|c|}{ Total Dana Klaim AUTP } & 1.500 .000 & & \\
\hline \multicolumn{5}{|c|}{ Perbandingan (Biaya/Klaim) } & 110,31 & Selisih Rp 140.218,00 \\
\hline
\end{tabular}

Sumber: Data primer, diolah (2017)

\section{Simpulan dan Saran}

\subsection{Simpulan}

Hasil penelitian disimpulkan bahwa (1) respons petani positif, dilihat dari pengetahuan dan sikap petani terhadap program AUTP; dan (2) pemanfaatan dana klaim AUTP menurut jenis penggunaan dana dan perbandingan dana klaim dengan biaya produksi termasuk efektif. 


\subsection{Saran}

Berdasarkan kesimpulan yang diperoleh, dapat disarankan hal-hal sebagai berikut (1) koordinasi yang terjalin antara pihak terlibat perlu dipertahankan untuk pelaksanaan AUTP selanjutnya; dan (2) program AUTP dapat dilanjutkan di Subak Sengempel dan perlu diterapkan pada subak dengan tingkat kegagalan panen tinggi akibat serangan OPT dan potensi kegagalan panen lainnya.

\section{Ucapan Terima Kasih}

Penulis menyampaikan terimakasih kepada pihak yang telah memberikan informasi yang mendukung penelitian yaitu PT Jasindo, Dinas Pertanian Provinsi Bali, seluruh responden beserta pangliman Subak Sengempel, serta PPL Desa Bongkasa.

\section{Daftar Pustaka}

Arikunto, S. 2002. Prosedur Penelitian Suatu Pendekatan Praktik. Jakarta: Rineka Cipta.

Badan Pusat Statistik. 2012. Proyeksi Penduduk Menurut Provinsi (2010 - 2035). [Online] http:// bps.go.id/. Diunduh tanggal 14 Agustus 2017.

Badan Pusat Statistik. 2013. Konsep dan Definisi Sensus Pertanian 2013. [Online] http://st2013.bps.go.id/. Diunduh tanggal 14 Agustus 2017.

Balai Penyuluhan Pertanian Kecamatan Abiansemal. 2015. Laporan Pengamatan OPT Utama BPP Kecamatan Abiansemal, Kabupaten Badung Tahun 2015.

Djojosoedarso, S. 1999. Prinsip-Prinsip Manajemen Resiko dan Asuransi. Jakarta: Penerbit Salemba Empat.

Insyafiah, I.W. 2014. Kajian Persiapan Implementasi Asuransi Pertanian Secara Nasional. Kemenkeu. Jakarta. [Online] http://www.kemenkeu.go.id/. Diunduh tanggal 19 Desember 2016.

Notoatmodjo, S. 2010. Ilmu Perilaku Kesehatan. Jakarta: Rineka Cipta.

Rahman, A.A. 2013. Psikologi Sosial. Jakarta: Raja Grafindo Persada.

Sugiyono. 2011. Metode Penelitian Pendidikan (Pendekatan Kuantitatif, Kualitatif, dan $R \& D)$. Bandung: CV Alfabeta.

Suryana, A. 2002. Kendala, Tantangan dan Kebijakan dalam Upaya Mewujudkan Pemantapan Ketahanan dan Kemandirian Pangan Nasional Ke Depan. [Online] http://pse.litbang.pertanian.go.id/. Diunduh tanggal 20 Desember 2016. 